\title{
OS DIREITOS HUMANOS DA PESSOA IDOSA NUMA PERSPECTIVA COMPARADA EM PAÍSES IBERO-AMERICANOS
}

\section{THE HUMAN RIGHTS OF THE ELDERLY PEOPLE IN A COMPARED PERSPECTIVE IN IBERO-AMERICAN COUNTRIES}

\section{LOS DERECHOS HUMANOS DE LA PERSONA MAYOR EN UNA PERSPECTIVA COMPARADA EN PAÍSES IBEROAMERICANOS}

Delcio Antônio Agliardi*

\begin{abstract}
Resumo: Este texto apresenta um estudo comparado de direitos humanos da pessoa idosa em países ibero-americanos e mostra as mudanças demográficas e o envelhecimento da população no território. Tem como objetivo explorar os documentos políticos e jurídicos que dão sustentação à promoção e proteção de direitos do idoso no Brasil, Chile, México e Uruguai. Propõe a ser a legislação insuficiente para o cuidado humano do idoso, por isso deve surgir uma nova cultura e uma nova ética para as relações afetivas entre as pessoas no mundo contemporâneo. O método de investigação utilizado é o de análise documental, que permite escolher alguns marcadores para a análise e compreensão do fenômeno escolhido, uma espécie de historiografia dos direitos humanos no período histórico pós-guerra. O Brasil, país que formulou nas últimas décadas a política, o plano nacional e o Estatuto do Idoso, é considerado como um caso singular entre os outros países ibero-americanos, pois a política do idoso, baseada em um enfoque de direitos, promove a construção da cidadania na velhice e garante, por parte do Estado, as condições para o exercício de direitos individuais e coletivos. O texto apresenta uma sustentação teórica em autores como Bobbio (1992), Maturana (2004) e Levinas (2005), entrelaçando conceitos. Os direitos e o cuidado humano da pessoa idosa são abordados numa concepção de cultura matrística (maternagem), ou seja, fundamentada na ética da alteridade, a partir do pensamento de Levinas, pois o rosto do idoso pede abrigo, cuidado e paciência.
\end{abstract}

Palavras-chave: Direitos humanos. Pessoa idosa. Estatuto do Idoso.

Abstract: This paper presents a comparative study of the Human Rights of the Elderly in IberoAmerican countries and shows the demographic changes and the aging of population in the territory. It explores the political and legal documents that support the promotion and protection of rights of the elderly in Brazil, Chile, Mexico and Uruguay. It proposes to be an insufficient legislation for the human care of the elderly, so that a new culture and a new ethic for the affective relationships of people in the contemporary world must emerge. The research method used is the documentary analysis, which allows us to choose some markers and to understand the phenomenon chosen, a type of historiography of the human rights in the postwar period. Brazil, which has formulated its policies, the national plan and the Statute of the Elderly in the last decades, is considered a unique case among the other Ibero-American countries, since the elderly's policy, based on a rights-based approach, promotes the construction of citizenship in old age and guarantees, by the State, conditions for the exercise of individual and collective rights. This work is based on theoretical support on authors such as Bobbio (1992), Maturana (2004) and Levinas (2005), interlacing concepts. The rights and the human care of the elderly people

\footnotetext{
* Universidade de Caxias do Sul - UCS. Email: daagliardi@ucs.br
} 
are approached in a conception of mothering, based on Levinas' thought on the ethics of otherness, once the face of the elderly asks for shelter, care and patience.

Keywords: Human Rights. Elderly. Statute of the Elderly.

Resumen: Este texto presenta un estudio comparado de derechos humanos de la persona mayor en países iberoamericanos. Muestra los cambios demográficos y el envejecimiento de la población en el territorio iberoamericano. Tiene como meta explorar los documentos políticos y jurídicos que dan apoyo a la promoción y protección de derechos del anciano en Brasil, Chile, México y Uruguay. Propone ser la legislación insuficiente para el cuidado humano del anciano. Por eso, debe surgir una nueva cultura y una nueva ética para las relaciones afectivas entre las personas en el mundo contemporáneo. El método de investigación utilizado es el análisis documental, que permite elegir algunos marcadores para el análisis y comprensión del fenómeno elegido, una especie de historiografía de los derechos humanos en el período histórico de pos guerra. El Brasil, país que formuló en las décadas recientes la política, el plan nacional y el Estatuto del Anciano, es considerado como un caso único entre los otros países iberoamericanos, pues la política del anciano, basada en un enfoque de derechos, promueve la construcción de la ciudadanía en la vejez y asegura, por parte del Estado, las condiciones para el ejercicio de derechos individuales y colectivos. El texto presenta una sustentación teórica en autores como Bobbio (1992), Maturana (2004) y Levinas (2005), entrelazando conceptos. Los derechos y el cuidado humano de las personas mayores son abordados en una concepción de cultura matrística (la maternidad), o sea, con base en la ética de la alteridad, desde el pensamiento de Levinas, pues el rostro del anciano pide cuidado, atención y paciencia.

Palabras-clave: Derechos humanos. Persona Mayor. Estatuto del Anciano

\section{Introdução}

Este texto apresenta uma reflexão sobre os direitos humanos da pessoa idosa numa perspectiva comparada em países ibero-americanos. Resulta de pesquisa ancorada em metodologia de análise documental, a partir da legislação e de políticas destinadas aos direitos da pessoa idosa em alguns países do território ibero-americano. Mostra como o processo de envelhecimento, sobretudo nos países em desenvolvimento, é rápido e apresenta grandes desafios para a sociedade, que não se vê preparada para essa nova realidade.

Analisa a formulação de política, plano nacional e lei especial no Brasil, Chile, México e Uruguai para compreender os movimentos políticos e jurídicos que estão em curso, visando sustentar a Doutrina da Proteção Integral de Direitos Humanos às pessoas com idade igual ou superior a 60 anos.
A partir da compreensão de que os direitos dos idosos começam a ganhar espaço na agenda internacional, surgem diversas abordagens, de cunho interdisciplinar, sobre o envelhecimento ativo, os problemas e as soluções coletivas que devem surgir na esteira desta temática.

O fenômeno, recente nos países ibero-americanos, decorre do aumento da taxa de expectativa de vida e da redução dos índices de natalidade. O Relatório do Fundo de População das Nações Unidas (UNFPA, 2012) mostra que a expectativa é de um perfil demográfico global muito diferente nos próximos anos. Estima-se que a população idosa poderá chegar, em 2020, a aproximadamente 1 bilhão de pessoas.

A comparação, via análise documental, não esgota as possibilidades de estudo sobre os diferentes aspectos no campo político e jurídico, imbricados com a problemática do 
envelhecimento humano na sociedade contemporânea. Segundo Abreu,

o ponto de partida de uma pesquisa não é a análise de um documento, mas a formulação de um questionamento. A problematização das fontes é fundamental porque elas não falam por si, são testemunhas, vestígios que respondem a perguntas que lhes são apresentadas (ABREU, 2008, s/p).

Deste modo, não interessa analisar os textos dos documentos jurídicos e políticos em si, mas as respostas que eles buscam dar aos problemas que surgem a partir do envelhecimento humano. É uma contribuição pontual para a reflexão em torno de alguns problemas decorrentes do contexto de influência e elaboração de políticas e das legislações na região ibero-americana e de sua prática para a efetivação de direitos humanos.

\section{Envelhecimento humano: uma tendência mundial}

O envelhecimento da população é uma tendência mundial. Porém, nos países desenvolvidos, o processo de envelhecimento humano ocorreu de forma lenta, se comparada com os países em desenvolvimento. De acordo com a Organização Mundial de Saúde (2005), o processo de envelhecimento dos países em desenvolvimento ocorreu em torno de 3 décadas, situação distinta dos países desenvolvidos, os quais vivenciaram este processo em torno de 1 século, tempo suficiente para a estabilidade econômica e a formulação de políticas e programas para o envelhecimento.

O envelhecimento da população é um dos maiores desafios para os países ibero-americanos, pois 80\% das pessoas idosas do mundo vivem em países em desenvolvimento. Esse contexto desafia os países deste território a promoverem ações de bem-estar econômico e social para quase 50 milhões de idosos.
A nova realidade demográfica dos países em desenvolvimento causa impactos sociais importantes, não previstos no âmbito das políticas públicas e nas organizações públicas e privadas. Como se sabe, o envelhecimento humano, maior percentual de pessoas idosas entre a população, decorre do aumento da expectativa de vida e da redução da taxa de fecundidade, número de filhos por mulher, o que resulta na diminuição da população, a longo prazo, e o seu envelhecimento.

De acordo com o Relatório do Fundo de População das Nações Unidas (UNFPA, 2012), a expectativa é de que o perfil demográfico global se altere significativamente nos próximos anos. Estima-se que a população idosa será, em 2020, de aproximadamente 1 bilhão de pessoas.

Ainda no ano de 1987, o documento World Health Statistics Annual previa um aumento exponencial da população idosa no mundo, sobretudo nos países em desenvolvimento, muito superior aos países desenvolvidos, conforme mostra o gráfico seguinte.

Gráfico 1: População idosa em países desenvolvidos e em desenvolvimento

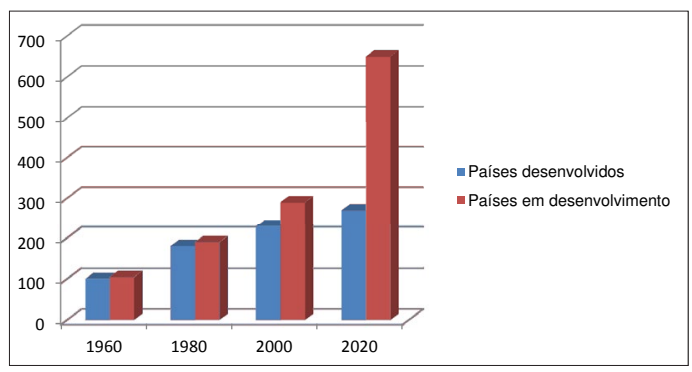

A última Pesquisa Nacional de Amostras de Domicílios (Pnad, 2012) demonstra que as pessoas com mais de 60 anos são, no Brasil, 12,6\% da população, isto é, 24,85 milhões de indivíduos. Em 1950 a taxa era de 4,2\%, em 2011 o percentual era de $12,1 \%$ e em 2002, 9,3\%. De acordo com 
o Pnad (2012), a maior parte da população idosa é mulher (13,84 milhões) e vive em áreas urbanas (20,94 milhões). Mostra também que em algumas Unidades da Federação, como nos Estados do Rio de Janeiro e do Rio Grande do Sul, a população já representa mais de $16 \%$ da população total. Este aumento no número de pessoas idosas é uma tendência que se observa há algum tempo.

Na Argentina, o número de pessoas idosas é de $10 \%$ da população, e a estimativa é que serão 10 milhões de pessoas em 2015. O índice da população idosa no Uruguai já está acima dos 18\%, ou seja, é uma proporção que se aproxima à da Europa, um recorde na América do Sul, situação que antecipa o que quase todos os países da região vão enfrentar no futuro próximo. Para demógrafos e economistas, esta alteração demográfica implicará uma série de mudanças nas políticas públicas, no sistema de transportes, saúde e previdência social, entre outros.

Um diagnóstico amplo sobre o envelhecimento humano nos países do Cone Sul - Brasil, Argentina, Uruguai e Paraguai - está sendo elaborado e faz parte do "Projeto Pessoas Idosas, Dependência e Serviços Sociais nos Países do Cone Sul.” Este projeto integra um conjunto de atividades de cooperação técnica que o governo brasileiro, por intermédio do Ministério do Desenvolvimento Social (MDS), mantém com a Organização Ibero-americana de Segurança Social (OISS), da Espanha. Ou seja, as organizações governamentais e não governamentais buscam estratégias para o enfrentamento da nova realidade, que é o aumento da população de pessoas idosas.

\section{A doutrina da proteção de Direitos Humanos e a pessoa idosa}

Segundo Bobbio (1992), os direitos humanos não nascem todos de uma única vez e também não são definitivos, mas surgem quando devem ou podem nascer. Portanto, são considerados direitos históricos. A noção de direitos humanos fundamentais não é um fenômeno novo, embora seja recente. A Declaração Universal dos Direitos do Homem (ONU, 1948), criada no período pós-guerra, abre caminho para a constituição e efetivação de garantias individuais, coletivas e difusas no âmbito dos direitos humanos em diversas regiões do mundo.

A partir deste momento, os países membros da ONU travaram lutas históricas visando, no contexto de influência internacional, à arquitetura jurídica para a implantação e implementação da Doutrina da Proteção de Direitos Humanos. Diante do contexto mundial, e especificamente nos países Iberoamericanos, a legislação e as políticas públicas para a pessoa idosa consistem em ações organizadas pelo Estado e pela sociedade civil frente às consequências sociais, econômicas e culturais do envelhecimento da população.

A legislação aqui é concebida como um arcabouço jurídico que garante o cumprimento dos direitos fundamentais da pessoa idosa. Política pública é entendida como uma ação do Estado frente a um problema de interesse público, efetivada na agenda governamental e que pode incluir um conjunto de medidas normativas, institucionais, administrativas e programáticas a serem desenvolvidas pelo Estado e, em alguns casos, em parceria com a sociedade civil e organizações sociais.

Na análise documental desta investigação observa-se que os países ibero-americanos têm construído políticas e legislação de modo heterogêneo. Na tabela seguinte dá para perceber que instrumentos políticos e jurídicos estão sustentando a garantia de direitos humanos da pessoa idosa. 
Tabela 1: Instrumentos políticos e jurídicos

\begin{tabular}{l|c|c|c}
\hline País & Política & Plano Nacional & Lei Especial \\
\hline Brasil & $\mathrm{x}$ & $\mathrm{x}$ & $\mathrm{x}$ \\
\hline Chile & $\mathrm{x}$ & & \\
\hline México & & & $\mathrm{x}$ \\
\hline Uruguai & & & $\mathrm{x}$ \\
\hline
\end{tabular}

A política para a pessoa idosa, no Brasil, surge a partir da aplicação da regra do artigo 204 da Constituição Federal de 1988, que prevê a descentralização político-administrativa (inciso I), combinada como a participação da população (inciso II), através de organizações representativas da sociedade, para a elaboração de políticas e para o controle das ações de implementação. A política destinada à pessoa idosa efetivar-se-á através da criação de conselhos de direitos - visando ao controle social e participação -, fundos de financiamento, conferências nas três esferas administrativas e articulação e cooperação entre organismos públicos e privados.

A política nacional do idoso, fortalecida pelo Estatuto do Idoso, determina a criação de conselhos de direitos das pessoas idosas nas três instâncias de governo, com competências específicas para a deliberação, implementação e controle social de ações.

No período histórico entre 1990 e 2014 são criados, no Brasil, diversos instrumentos jurídicos, na forma de política, plano e lei especial, que asseguram direitos humanos de crianças, adolescentes, jovens, mulheres, idosos, entre outros. O Estatuto da Criança e do Adolescente, aprovado em 1990, que dispõe sobre a Doutrina da Proteção Integral à criança e ao adolescente, alimentou importante influência sobre a elaboração de outros textos jurídicos destinados a segmentos da sociedade, como é o caso do Estatuto do Idoso, aprovado em 2003.

A comparação entre o texto do Estatuto da Criança e do Adolescente (Lei Federal 8.069/1990) e do Estatuto do Idoso (Lei Federal 10.741/2003) mostra que são similares, tanto no conteúdo quanto na arquitetura geral do texto. A tabela abaixo comprova este alinhamento das leis, de modo especial nas medidas específicas de proteção, na política de atendimento, no funcionamento e na fiscalização das entidades de atendimento, nas infrações administrativa e crimes.

Tabela 2: Comparação da legislação

\begin{tabular}{l|l}
\hline $\begin{array}{l}\text { Art. } 4 \text { - Estatuto } \\
\text { da Criança }\end{array}$ & $\begin{array}{l}\text { É dever da família, da comunidade, da sociedade em geral e do poder público } \\
\text { assegurar, com absoluta prioridade, a efetivação dos direitos referentes à vida, } \\
\text { à saúde, à alimentação, à educação, ao esporte, ao lazer, à profissionalização, à } \\
\text { cultura, à dignidade, ao respeito, à liberdade e à convivência familiar e comunitária. }\end{array}$ \\
\hline $\begin{array}{l}\text { Art. } 3 \text { - Estatuto } \\
\text { do Idoso }\end{array}$ & $\begin{array}{l}\text { É obrigação da família, da comunidade, da sociedade e do poder público assegurar } \\
\text { ao idoso, com absoluta prioridade, a efetivação do direito à vida, à saúde, à } \\
\text { alimentação, à educação, à cultura, ao esporte, ao lazer, ao trabalho, à cidadania, à } \\
\text { liberdade, à dignidade, ao respeito e à convivência familiar e comunitária. }\end{array}$ \\
\hline $\begin{array}{l}\text { Art. } 98 \text { - Estatuto } \\
\text { da Criança }\end{array}$ & $\begin{array}{l}\text { A política de atendimento dos direitos da criança e do adolescente far-se-á através } \\
\text { de um conjunto articulado de ações governamentais e não-governamentais, da } \\
\text { União, dos estados, do Distrito Federal e dos municípios. }\end{array}$ \\
\hline Art. $46^{\circ}$ - & $\begin{array}{l}\text { A política de atendimento ao idoso far-se-á por meio do conjunto articulado de } \\
\text { Esçães governamentais e não-governamentais da União, dos Estados, do Distrito } \\
\text { Federal e dos Municípios. }\end{array}$ \\
\hline
\end{tabular}


A partir da Constituição Federal de 1988, que prima pela garantia dos direitos individuais e sociais da pessoa, fruto da organização e participação ativa dos movimentos sociais das décadas de 1960 e 1970, abriu-se espaço na agenda política para uma nova conjuntura de afirmação de direitos.

O Chile criou, em 1998, La Política Nacional para el Adulto Mayor e, no ano de 2002, promulgou a Lei $n^{0} 19.828$, que cria o Servicio Nacional para el Adulto Mayor, firmando as bases na lógica de uma política de Estado. Os documentos afirmam que a política nacional para o "adulto maior" estabelece um marco referencial e uma finalidade de caráter permanente que deverá sustentar as diferentes ações que se propõe realizar em favor do idoso.

A análise documental da política nacional da pessoa adulta maior do Chile mostra aspectos similares com a política nacional do idoso do Brasil. Descentralização, participação e integração social, equidade social, envelhecimento ativo, prevenção, melhorar o sistema destinado à pessoa institucionalizada são alguns dos aspectos que se aproximam.

De acordo com o documento chileno (1998), a política sinaliza uma necessidade de assumir o envelhecimento como uma preocupação, tanto do Governo como de toda a sociedade. O Servicio Nacional para el Adulto Mayor, criado em 2002), vinculado ao Ministério do Desenvolvimento Social, é responsável por diversos programas, entre os quais os principais são os seguintes: (a) Financiamento: cria o Fundo Nacional do Adulto Maior e o Fundo para Estabelecimentos de Longa Permanência; (b) Integração Social, que prevê o Serviço de Convivência para o Adulto Maior, o Programa Te Acompanho e Programa de Cuidadores Domiciliares; (c) Empreendedorismo, através do Turismo Social, Assessores Seniores e do Programa de
Participação e Formação (escola de dirigentes); (d) Acolhimento institucional, que cria o Centro Dia e o Programa para o Cuidado do Adulto Maior.

Nos outros países em análise, México e Uruguai, foram criadas leis especiais para a proteção dos direitos da pessoa idosa. O México criou a Ley de Derechos de las Personas Adultas Mayores, em 2002, e o Uruguai a Lei chamada de Política General em Matéria de Ancianidad.

Os princípios da lei dos direitos do idoso do México se aproximam dos outros países ibero-americanos, ou seja, participação, equidade, corresponsabilidade e atendimento preferencial. A Ley de Derechos de las Personas Adultas Mayores cria, no México: a política nacional para os direitos das pessoas adultas maiores; os princípios, objetivos e programas e responsabilidades da administração pública; o Instituto Nacional das Pessoas Adultas Maiores.

No Brasil, a política voltada para a pessoa idosa tem a finalidade de assegurar os direitos sociais do idoso, criando condições para promover sua autonomia, integração e participação efetiva na sociedade. No Chile, as políticas públicas estão dirigidas para a integração familiar e social efetiva da pessoa idosa e para a solução dos problemas que afetam essa população. A “Política Nacional para o Adulto Maior” estabelece áreas de intervenção concretas, buscando formas de garantir os direitos do idoso.

Observa-se que, embora heterogêneos, os instrumentos jurídicos analisados representam um avanço no que diz respeito à garantia de direitos humanos, estabelecendo que o idoso goza de todos os direitos fundamentais inerentes à pessoa humana, sendo-lhe asseguradas todas as oportunidades e facilidades para a preservação de sua saúde física e mental e o aperfeiçoamento moral, intelectual, 
espiritual e social, em condições de liberdade e dignidade.

Um aspecto diferente na análise documental comparativa, entre os países ibero-americanos, mostra que o Brasil avançou em relação ao controle social. Na legislação brasileira estão previstos diversos instrumentos para assegurar a participação popular na formulação, deliberação e controle da política destinada às pessoas idosas. As conferências e os conselhos são espaços de articulação entre as organizações governamentais e as da sociedade civil com a finalidade de garantir os direitos humanos do idoso.

De acordo com Gugel (2009, p. 216), "os conselhos de direitos, em todos os níveis da federação (nacional, estadual e municipal), retratam um modo de descentralizar as atividades do Estado.” Porém, o processo de descentralização das atividades estatais envolve outros elementos conceituais que complementam o trabalho dos conselhos de direitos: o controle social e a participação.

Os Conselhos do Idoso (nacional, estaduais e municipais) são instâncias colegiadas de caráter permanente e deliberativo que integram a estrutura básica do Estado, responsável pela promoção da cidadania. A composição é paritária, de modo a garantir a participação da sociedade no controle do sistema de promoção e defesa da pessoa idosa.

\section{As leis não bastam, os lírios não nascem das leis}

A expressão acima é extraída da obra Rosa do Povo, do poeta Carlos Drummond de Andrade (2012), para sinalizar que a garantia dos direitos humanos da pessoa idosa efetivar-se-á por meio de uma nova cultura de cuidado humano. Neste sentido, as leis não bastam. É necessário ir além, ou seja, criar uma cultura que supere o paradigma do patriarcado. Humberto Maturana (2004) propõe uma nova configuração que denomina de "cultura matrística".

A cultura do patriarcado, gestada na maneira de viver do patriarcado europeu, tem como características a competição, a luta, as hierarquias, a autoridade, o poder, a dominação dos outros por meio da apropriação da verdade. Essa tradição cultural separou corpo e mente, corpo e espírito, que resulta em sofrimento, fanatismo, violência e dor.

Noutra perspectiva, a cultura matrística tem como fundamento a "maternagem", definida para além da relação materno-infantil que envolve a mãe, não como mulher, mas como um adulto numa relação de cuidado. Desta forma, pode-se sugerir que a proteção da pessoa idosa envolve a maternagem enquanto uma relação de cuidado. Somos filhos do amor, pertencemos à biologia do amor. De acordo com Maturana (2004, p. 45), “a emoção que estrutura a coexistência social é o amor, ou seja, o domínio das ações que constituem o outro como um legítimo outro em coexistência”.

Durante muito tempo acreditou-se que os pais cuidariam de seus filhos na infância para que eles cuidassem dos pais na velhice. Uma ética da reciprocidade, portanto. Mas, com as grande transformações sociais que afetam a família pós-moderna, essa verdade está ameaçada. Para Bauman (2008, p. 8), "todas as sociedades são fábricas de significados. Até mais que isso: são as sementeiras da vida com sentido". E como garantir, então, o cuidado da pessoa idosa se não há certeza de que os filhos cuidarão de seus pais?

Encontramos uma possível saída para este problema na ética da alteridade, defendida por Levinas, que sugere a instalação da consciência ética no encontro com o outro, face a face, olhos nos olhos, uma instalação do humano. Nesta perspectiva, a pessoa idosa 
não será protegida pela força da lei ou pela ótica da reciprocidade, mas porque todo e qualquer idoso é merecedor de cuidado humano. Segundo Levinas (2005), o rosto do outro pede abrigo, cuidado e sacrifício.

O rápido envelhecimento da população nos países em desenvolvimento, associado às diversas transformações em curso na sociedade pós-moderna, geram cenários desafiadores, que somente pela força da lei não será possível enfrentar. A política, os planos nacionais e a legislação especial são conquistas de todos os cidadãos e representam um enorme avanço para a garantia de direitos, mas não são suficientes. É preciso criar as condições no âmbito da família e da sociedade para evitar a ameaça ou violação de direitos, a promoção do envelhecimento ativo e o bem-estar do idoso.

Com o rápido envelhecimento da população, há riscos de aumento significativo de pessoas em casas asilares de longa permanência. Situação que implica a ameaça de fragilização ou rompimento de vínculos familiares ou comunitários. O artigo 49 do Estatuto do Idoso obriga as entidades que desenvolvem programas de institucionalização de longa permanência a adotarem, entre outros, os seguintes princípios: (a) preservação de vínculos familiares; (b) participação do idoso nas atividades comunitárias, de caráter interno e externo.

Contudo, as leis em defesa dos idosos nos países em desenvolvimento precisam ser aprimoradas. Muitas sequer são aplicadas por falta de informação e comunicação. No Brasil, mesmo com a aprovação do Estatuto do Idoso, em 2003, reiterando o que estava escrito na Constituição Federal de 1988 e na Lei $n^{\circ} 8.842$ de 1994, que instituiu a política nacional do idoso, os princípios ainda não são considerados na sua totalidade pela sociedade, muito menos na formulação e execução das políticas públicas dos estados e municípios. Embora o Brasil seja um dos países mais avançados do mundo em termos da legislação nacional ao idoso, ainda não conseguiu universalizar o acesso aos direitos fundamentais à pessoa idosa.

Nos países ibero-americanos existem leis, analisadas neste trabalho, mas estão longe de serem colocadas em prática. Além dos profissionais e operadores do direito não estarem qualificados para o atendimento das pessoas nesta faixa etária, os próprios idosos não foram preparados para envelhecer. É preciso uma mudança de cultura. E esta transformação passa pela educação escolar e não escolar.

Por outro lado, “a idade merece um tratamento mais referencial que cronológico, que reflita variações e percepções, expectativas, metas e objetivos para cada situação pessoal” (MONTAÑES et al, 2012, p. 65). Deste modo, as questões ligadas à saúde, satisfação e bem-estar do idoso desafiam as organizações públicas e privadas a qualificar os atendimentos, de maneira a garantir serviços essenciais para todos os idosos.

Os problemas ou o temor da solidão e do isolamento, a perda de memória, a dependência do outro, a insegurança financeira, as incertezas frente ao futuro e o medo da morte são discursos frequentes entre esta população. Portanto, a rede de relações sociais e familiares de pessoas acima de 60 anos de idade assume relevância e importância na sociedade contemporânea.

\section{Considerações finais}

Alguns países ibero-americanos criaram leis especiais, planos e políticas para promoção e proteção dos direitos humanos da pessoa idosa nas últimas décadas do século XX e nas primeiras do século XXI. Apesar de todas as conquistas que a população idosa 
vem alcançando nas últimas décadas, através da participação e luta pelos direitos humanos, da adoção de novas concepções sobre o envelhecimento ativo e constituição de fóruns, ainda persiste a situação de ameaça ou violação de direitos humanos da pessoa idosa. Outros aspectos precisam ser aprimorados na legislação e, sobretudo, na efetivação de serviços, programas e projetos de qualidade social.

A mudança no perfil demográfico da população ibero-americana impõe desafios importantes para as políticas públicas de seguridade social, atendimento diante de ameaça ou violação de direitos, mobilidade urbana, sistema público de saúde, entre outros.

A mudança na cultura dos cuidados à pessoa humana, que na concepção de Maturana (2004) é uma forma de maternagem, pode se somar à legislação para proteger e estimular o desenvolvimento intelectual e afetivo das pessoas depois dos 60 anos de idade. Mais do que a emergência na implantação da legislação e da efetividade das políticas públicas nos países Ibero-americanos será necessária uma nova prática de atenção à pessoa idosa.

\section{Referências}

ABreu, S. E. A. Pesquisa e análise documental. 2008. Disponível em http:// www.unievangelica.edu.br/gc/imagens/ noticias/1817/file/01.pdf. Acesso em 15/03/2015.

ANDRADE, C. D. A rosa do povo. São Paulo: Companhia das Letras, 2012.

BAUMAN, Z. A sociedade individualizada: vidas contadas e histórias vividas. Rio de Janeiro: Zahar, 2008.

BOBBIO, N. A era dos direitos. Rio de Janeiro: Campus, 1992.
BRASIL. Estatuto do Idoso. Lei Federal $n^{\circ}$ 10.741. Brasília, 2003.

CHILE. Política nacional para el adulto mayor. Disponível em http://www.cepal. org/celade/agenda/1/10761/polNac_chile. pdf. Acesso em 13/03/2015.

LEVINAS, E. Entre nós: ensaio sobre a alteridade. Petrópolis: Vozes, 2005.

MATURANA, H. Amar e brincar: os fundamentos esquecidos do humano. São Paulo: Palas Athena, 2004.

MÉXICO. Ley de Derechos de las personas adultas mayores. Disponível em http://www.diputados.gob.mx/LeyesBiblio/ pdf/245.pdf. Acesso em 14/03/2015.

MONTAÑÉS, M. C. M. et al. Qualidade de vida no envelhecimento. In: AREOSA, S. V. C. (Org.). Envelhecimento humano: realidade familiar e convício social de idosos no Rio Grande do Sul (Brasil) e da Catalunha (Espanha). Porto Alegre: EDIPUCRS, 2012.

Organização Mundial da Saúde. Envelhecimento ativo: uma política de saúde. Brasília, Organização Pan-americana da Saúde, 2005.

URUGUAI. Política general em matéria de ancianidad. Disponível em http://www. elderechodigital.com.uy/acceso1/legisla/ decretos/d9900320.html. Acesso em 13/03/2105. 